\title{
Patterns of Violence Against Adults and Children During the COVID-19 Pandemic in Kenya
}

Sarah Rockowitz ${ }^{1}$, Laura M. Stevens ${ }^{1}$, James Rockey ${ }^{1}$, Lisa Smith ${ }^{2}$, Jessica Richie ${ }^{2}$, Melissa Colloff $^{1}$, Wangu Kanja ${ }^{3}$, Jessica Cotton ${ }^{1}$, and Heather Flowe ${ }^{1}$

\author{
University of Birmingham, School of Psychology ${ }^{1}$ \\ University of Leicester, School of Criminology ${ }^{2}$ \\ The Wangu Kanja Foundation ${ }^{3}$
}

\begin{abstract}
Author Note
We thank the Survivors of Sexual Violence Network in Kenya and the Social Justice Network Group for collecting the data for this study, and for the survivors who shared their stories with us.

Our data are available

(https://osf.io/bqrn2/?view_only=4536951b3a9640078649b2e4cdfc956f).

This work was supported by an ESRC Grant (to H.D.F., M.F.C., J.C.R. and W.K.F.), the Institute for Global Innovation, University of Birmingham (to H.D.F, and W.K.F.), and a research grant from the Ring for Peace Foundation (to L.S.).

Sections of these data were included in a preliminary report and policy brief (https://zenodo.org/record/3964124\#.X-OVdGacYWo; and https://zenodo.org/record/3964162\#.X-OVk2acYWo)

Correspondence concerning this article should be addressed to Heather D. Flowe, School of Psychology, University of Birmingham, Birmingham, B15 2TT. Email: h.flowe@bham.ac.uk
\end{abstract}




\begin{abstract}
Objectives This study examined patterns of sexual violence against adults and children in Kenya
\end{abstract} during the COVID-19 pandemic to inform sexual violence prevention and protection efforts.

Design A prospective cross-sectional research design was used.

\title{
Setting Kenya
}

Participants 317 adults, 224 children

Main Measures Perpetrator and survivor demographic data, characteristics of the assault.

Results Children were more likely than adults to be attacked during the daytime, by a single perpetrator rather than multiple perpetrators, and in a private as opposed to a public location. Children were violated most often by neighbors and family members, whereas adults were equally likely to be attacked by strangers and persons known to them. On average, the children in the sample were four years younger compared to the average age reported in national samples pre-pandemic (age 12 versus 16). Survivors were more likely to be female than male.

Conclusions Patterns of sexual violence against adult and child survivors during the COVID-19 pandemic are different, suggesting age-related measures are needed in national emergency plans to adequately address sexual violence during the pandemic. 
VIOLENCE DURING COVID-19 IN KENYA

\section{Strengths and limitations of this study}

This study was conducted in partnership with frontline, survivor-led organisations, using a prospective study design, which enabled the systematic and rapid study of sexual violence in Kenya during the pandemic, even though there were considerable physical distancing measures in place.

The data provide detailed information about survivors and perpetrators, including where and when incidents occurred, which enabled us to compare patterns of sexual violence in adults and children.

The sample was comprised of individuals who were seeking help in accessing vital services; therefore, inferences about patterns nationally in Kenya cannot be made because the data may not be a representative.

Information about whether patterns of sexual violence are changing during the pandemic remains unknown because sexual violence is underreported, and there is a need for real time data collection systems that gather and analyse detailed, longitudinal information about sexual violence incidents in low- and middle-income countries like Kenya. 
VIOLENCE DURING COVID-19 IN KENYA

\section{Patterns of Violence Against Adults and Children During the COVID-19 Pandemic in Kenya}

Sexual and gender-based violence (SGBV) affects women in all societies. Nearly a third of ever-partnered women worldwide have experienced physical and/or sexual intimate partner violence at least once in their lives, and $7.2 \%$ of all women have experienced non-partner sexual violence. ${ }^{1}$ This study focuses on Kenya, a country that has a long history of SGBV, which is exacerbated during times of national crisis, such as during election periods. ${ }^{2}$ Previous conflicts and disasters have led to increased gender inequality, gender-based violence and other human rights violations, owing to disruptions in medical, protection, and legal services. ${ }^{3}$ The arrival of COVID-19 in Kenya in early March 2020 marked the start of another national crisis, with more than 56,000 Kenyans becoming sick as of November $2020 .^{4-6}$ In late March, President Kenyatta issued a nation-wide curfew, with all non-essential travel banned between $7 \mathrm{pm}$ to $5 \mathrm{am}$. Schools and non-essential businesses had to close, and travel in and out of the country was heavily restricted..$^{5,6}$ These measures have been extended and modified multiple times, and as of November 2020, the number of people who can gather in groups is still limited. Schools are still closed, while universities have been opened, and air travel restrictions have been lifted. ${ }^{6}$ While the measures have undoubtedly curbed the spread of the disease, they seem to be compromising the safety and well-being of citizens. In particular, there have been widespread reports of increases in domestic and sexual violence during the COVID-19 crisis. ${ }^{6,7}$ Indeed, there is worldwide concern that the pandemic will exacerbate gender inequality, and negatively impact the care and treatment women and girls receive in the aftermath of violence, owing to decreased access and funding following COVID-19 economic shocks. ${ }^{8}$ 
VIOLENCE DURING COVID-19 IN KENYA

Around the world, humanitarian crises, such as natural disasters, conflict, and disease outbreaks, are associated with changing patterns of sexual violence. ${ }^{9-12}$ After the 2010 earthquake in Haiti, for example, the odds of an adolescent girl in Haiti being sexually abused increased by $41 \% .{ }^{11}$ There have also been documented increases of violence against women after floods, hurricanes, and earthquakes in the United States, Canada, and Australia, as well as following the 2004 tsunami in Sri Lanka, and droughts in Ethiopia, Zimbabwe, and Kenya. ${ }^{13,14}$ Increased sexual violence occurs during conflicts, notably in Rwanda, Kosovo, and the Democratic Republic of the Congo (DRC). Sexual violence in these contexts has been used as a means of ethnic cleansing against the Tutsis, Kosovars, and Congolese women by the Hutus, Serbians, and Congolese soldiers, respectively. ${ }^{15-18}$ These crimes are especially prevalent against women and children, and attacks by multiple perpetrators are common. In the DRC, for example, nearly $76 \%$ of women surveyed had experiences of rape that were consistent with the attack being used as a weapon of war, and $69 \%$ of women reported experiencing gang rape, with these incidents typically being perpetuated by three perpetrators on average. ${ }^{17}$ These findings are consistent with research conducted in the Central African Republic, Libya, and Mali, which found that multiple-perpetrator rape was commonly reported by survivors. ${ }^{19}$

SGBV increases during disease outbreaks, with studies reporting increases in Sierra Leone, Liberia, and Guinea during the Ebola outbreaks in West Africa in 2014-2016, and especially high increases in teenage pregnancies were reported in Sierra Leone. ${ }^{12,}{ }^{20}$ Similarly, Zika and cholera outbreaks have been linked with increased incidence of domestic violence, and reductions in funding for and access to public health services. ${ }^{21}$ Physical distancing measures implemented during pandemics are also thought to be responsible for changing patterns and increases in violence. For instance, lockdowns and curfews mean that people have to remain 
VIOLENCE DURING COVID-19 IN KENYA

indoors with abusers and are unable to access outside assistance because police and vital services are unavailable, and abusers can act with impunity. ${ }^{22,}{ }^{23}$

More research on SGBV during times of compounding crises is needed, however. Genderbased violence is highly stigmatized, which leads to underreporting, especially in developing countries that have high levels of gender inequality. Further, it is difficult to assess whether patterns and rates of SGBV are changing during times of crisis, owing to the unavailability of nationally representative data and a lack of up-to-date and recurring data collection, which would allow for examining SGBV trends in relation to humanitarian crises, and inform effective prevention, protection and responses.

During the current COVID-19 outbreak, seven months of lockdown measures, economic challenges, health concerns, and changing global relations have increased concerns that women have a heightened risk of SGBV. This violence during lockdown is being considered a shadow pandemic with the UN Population Fund estimating an additional 31 million cases of SGBV worldwide following 6-months isolation. ${ }^{23,24}$ This increased risk of violence and abuse for women is coupled with other gendered impacts of the pandemic, including the gendered nature of healthcare (e.g., 70\% of the healthcare and social services workforce globally are women) putting women at increased chance of exposure, increased caregiving responsibilities, and a loss of informal sector work and therefore financial freedom. ${ }^{25}$ Governments in some countries, for example, have had to create or supply alternate housing for people fleeing abusive situations, as was the case with in Italy and France, with hotels being used as safe houses. ${ }^{26}$ Social isolation policies have distinct impacts on children as well. Adolescent girls' absence from school, coupled with the lack of alternative safe venues, has been associated with increased vulnerability to sexual violence from family members and others, including neighbours and 
VIOLENCE DURING COVID-19 IN KENYA

community members. ${ }^{27}$ As seen during the Ebola crisis, the closure of schools was associated with increased sexual violence against girls, adolescent pregnancy, and adolescent marriage. ${ }^{28}$

This study prospectively investigated patterns of sexual violence perpetrated against adults and children in Kenya during the COVID-19 pandemic. We analyse data from interviews with adult survivors and the guardians of child survivors conducted by human rights defenders during the pandemic. We focus on sexual violence because it has received less attention during the pandemic compared to other forms of gender-based violence. Further, research to date has not compared patterns of violence for adults and children. Doing so is critical because social isolation measures may differentially affect people in relation to age, and different measures may need to be put in place depending on the age group to prevent and respond to SGBV during COVID-19.

Based on the literature reviewed above, we predicted that there would be a greater number of women and girls violated compared to men and boys. Additionally, we anticipated there would be age-related differences in the types of locations in which sexual violence is occurring. Owing to school closures, and a lack of alternative safe spaces, we predicted that children would be at a greater risk than adults during the day, in private compared to public locations. We also compared the incidence of multiple versus single perpetrator attacks to better understand the nature of the violence occurring in relation to age. To our knowledge, no previous research has compared adults and children regarding the prevalence of violations committed by multiple perpetrators. Hence, no age group predictions were made concerning multiple perpetrators.

\section{METHOD}

\section{Design}


VIOLENCE DURING COVID-19 IN KENYA

A quantitative between groups prospective research design was used. The criterion variable was age group (child or adult survivor). The predictor variables included the offense characteristics displayed in Table 1, which also summarises how the variables were operationalized. 
Table 1

Descriptions of how predictor variables were coded and operationalised

\begin{tabular}{|c|c|}
\hline Variable & Definition \\
\hline Female Survivor & Whether the survivor was female (coded as 1 ) as opposed to male (coded as 0 ) \\
\hline Male Perpetrator & Whether the perpetrator was male (coded as 1 ) as opposed to female (coded as 0 ) \\
\hline Daytime Attack & $\begin{array}{l}\text { Whether the attack occurred in the daytime }(6: 00 \mathrm{am}-5: 59 \mathrm{pm} \text {; coded as } 1) \text { as opposed to at night } \\
(6: 00 \mathrm{pm}-5: 59 \mathrm{am} \text {; coded as } 0)\end{array}$ \\
\hline Private or Public Location & $\begin{array}{l}\text { Whether the attack occurred in a private home (coded as } 1 \text { ) as opposed to a public location where } \\
\text { the violation could have been witnessed or interrupted by a member of the public (coded as } 0 \text { ). }\end{array}$ \\
\hline Private Location Type & $\begin{array}{l}\text { Private locations were further subdivided into victim residence (coded as } 1 \text { for victim residence, } 0 \\
\text { for any other location public or private); perpetrator residence (coded as } 1 \text { for perpetrator } \\
\text { residence, } 0 \text { for any other location public or private); or other residence (coded as } 1 \text { for other } \\
\text { residence, } 0 \text { for any other location public or private). }\end{array}$ \\
\hline Multiple Perpetrator & $\begin{array}{l}\text { Whether the attack was perpetrated by more than one perpetrator (coded as } 1 \text { ) as opposed to a } \\
\text { singular perpetrator (coded as } 0 \text { ). }\end{array}$ \\
\hline $\begin{array}{l}\text { Known or Stranger } \\
\text { Perpetrator }\end{array}$ & $\begin{array}{l}\text { Whether the attack was perpetrated by someone known to the survivor (coded as } 1 \text { ) or a stranger } \\
\text { (coded as } 0 \text { ) }\end{array}$ \\
\hline $\begin{array}{l}\text { Perpetrator Relationship } \\
\text { Type }\end{array}$ & $\begin{array}{l}\text { Perpetrator relationship type was subdivided into neighbour (coded as } 1 \text { for neighbour, } 0 \text { for any } \\
\text { other relationship type); stranger (coded as } 1 \text { for stranger, } 0 \text { for any other relationship type); } \\
\text { family member (coded as } 1 \text { for family member, } 0 \text { for any other relationship type); } \\
\text { acquaintance/friend (coded as } 1 \text { for acquaintance/friend, } 0 \text { for any other relationship type); } \\
\text { spouse/husband/boyfriend (coded as } 1 \text { for spouse/husband/boyfriend, } 0 \text { for any other relationship } \\
\text { type); authority figure (coded as } 1 \text { for authority figure, } 0 \text { for any other relationship type); or other } \\
\text { (coded as } 1 \text { for other, } 0 \text { for any other relationship type). }\end{array}$ \\
\hline
\end{tabular}




\section{Participants}

Participants $(N=787)$ were survivors of sexual violence. All were residents of Kenya, living in 23 counties, and had contacted human rights defenders for assistance in obtaining vital services in the aftermath of sexual violence during the COVID-19 pandemic. The human rights defenders interviewed the survivors (or their legal guardians if they were under 18) about the offense upon intake. The interview protocol was informed by WHO ethical principles for research on SGBV and safety protocols developed by the human rights defenders for conducting their work with survivors. ${ }^{29}$ The survivors were aged between 7 months and 72 years $(M=21.3 ; S D=9.4)$.

Survivors were categorized into two age groups. Following definitions provided by WHO, the child group included survivors aged 17 years and younger, whereas the adult group included survivors aged 18 years and older. ${ }^{1}$

After excluding cases with missing data on the predictor variables, the final sample consisted of 224 survivors in the child group and 317 in the adult group. The participants in the final sample for the child group ranged in age from 8 months to 17 years $(M=12.6, S D=3.9), 83 \%$ were girls, and 93\% were perpetrated against by men, and for the adult group, ranged in age from 18 to $72(M=27.1, S D=8.1), 92 \%$ were women, and $96 \%$ were perpetrated against by men.

\section{Materials}

The data were obtained from records held by the human rights defenders who were assisting survivors in accessing vital services during the pandemic. They interviewed survivors about the incident and recorded information about the case on their standard intake form. They recorded the date, time, and location of the incident, and gave a free text description summarising the incident. The form also had specific items to document the number of perpetrators, the relationship between the survivor and perpetrator(s), the location of the attack, and the age and gender of the survivor 
and perpetrator. Additionally, whilst not analysed in the current paper, any services (e.g., police, medical, safe house) the survivor had accessed were also recorded.

\section{Procedure}

Each intake form was read by two members of the research team to create the dataset. They coded the data using the criteria outlined in Table 1. If there was missing data on the form, the team read the incident summary and attempted to complete the missing information.

\section{Ethics}

The confidentiality of the data was maintained by the research team, and participants were not placed at risk of harm as a result of this study. The Kenyan Data Protection Act (2019) was adhered to in the conduct of this research study. ${ }^{30}$ The data belong to the Wangu Kanja Foundation and the Sexual Violence Survivors' Network in Kenya, and permission to use the data was obtained from these organisations to conduct the analyses. The research was also approved by the STEM Ethics Committee at the University of Birmingham.

\section{Patient and Public Involvement}

We relied heavily on input from civil society grassroots organisations who work on the frontlines to assist suvivors in accessing vital services in the aftermath of sexual violence, including the Wangu Kanja Foundation and the Sexual Violence Survivors' Network in Kenya. These organisations co-developed of the research questions, the study design, including the data collection instruments, as well as participant recruitment, data collection, and manuscript preparation. Their experience and knowledge with sexual violence in Kenya informed every aspect of the project. Their reputation within the Kenyan communities enabled survivors to disclose the incidents that occurred. The Wangu Kanja Foundation and Human Rights Defenders 
will be integral in disseminating the research findings to their networks and relevant stakeholders.

\section{Statistical analysis}

As our main analysis, we used logistic regression with age group as the dependent variable to determine which offense characteristics significantly differentiated the child and adult groups. The child age group was coded as 1 in the analysis, whereas the adult age group was coded as 0 . While our data contain detailed information about each attack we restrict our analysis to a limited number of binary variables in Table 1 as predictors. This is because there is a risk of a common-support problem if we use a finer grained analysis. For example, whilst we have detailed data on where survivors were attacked, or relationship with the perpetrator, we cannot exploit this as few in the child group were attacked going to work, or by their spouse or partner. To avoid this difficulty, we used the coarser coding of relationship, known versus stranger perpetrator, and whether the attack took place in a public place or in private. This ensured that there were sufficient numbers of both children and adults in all categories. We then supplement this analysis by tabulating the finer coding in Tables 2 and 3 respectively.

\section{Table 2}

Distribution of Perpetrator Relationship to Survivor within Age Group

\begin{tabular}{lcc}
\hline & $\begin{array}{c}\text { Child } \\
n=224\end{array}$ & $\begin{array}{c}\text { Adult } \\
n=317\end{array}$ \\
\cline { 2 - 3 } Neighbour & $29 \%$ & $6 \%$ \\
Stranger & $25 \%$ & $41 \%$ \\
Family member & $20 \%$ & $5 \%$ \\
Other & $12 \%$ & $16 \%$ \\
Acquaintance/friend & $11 \%$ & $12 \%$ \\
Spouse/husband/boyfriend & $3 \%$ & $15 \%$ \\
Authority figure & $2 \%$ & $6 \%$ \\
\hline
\end{tabular}




\section{Table 3}

Distribution of Attack Location within Age Group

\begin{tabular}{lll}
\hline & Child & Adult \\
& $n=224$ & $n=317$ \\
\cline { 2 - 3 } Perpetrator's house & $41 \%$ & $20 \%$ \\
Public & $28 \%$ & $48 \%$ \\
Survivor's house & $23 \%$ & $23 \%$ \\
Other house & $7 \%$ & $6 \%$ \\
Survivor/perpetrator's house & $1 \%$ & $3 \%$ \\
\hline
\end{tabular}

We conducted preliminary analyses to identify which variables to enter into the model using Pearson's chi square tests for association. This allowed for testing whether the association between age group and each of the dichotomous variables was statistically significant. Only the variables that were significantly associated with age group were entered into the logistic regression model. To control for Type 1 errors, Bonferroni corrections were applied to the .05 alpha level (adjusted alpha $=.008$, with 6 variables). The strength of the relationship between the individual offense characteristics was assessed using Cramer's V, which measures the magnitude of the relationship between two categorical variables. ${ }^{31}$ Values that fall between .40 and .60 are interpreted as large, whereas values that fall between .20 and .40 are interpreted as moderate in magnitude. Values smaller than .20 are regarded as associations that are small in magnitude. All analyses were conducted using SPSS version 26.

Our data are freely available: https://osf.io/b9dzp/.

\section{RESULTS}

The results of the chi square analysis are presented in Table 4. Results indicate that children compared to adults were less likely to be female and less likely to be attacked by multiple perpetrators. Children compared to adults were more likely to be attacked in a private location, by 
a known perpetrator and were more likely to be attacked in the daytime. The association between age and private location, and age and multiple perpetrators was moderately large, whereas the strength of the other associations, while statistically significant, was small in magnitude.

\section{Table 4}

Chi Square Outputs

\begin{tabular}{|c|c|c|c|c|c|}
\hline & Child & Adult & Pearson's Chi Square & $p$ & $\begin{array}{c}\text { Cramer's } \\
\mathrm{V}\end{array}$ \\
\hline Variable & $n=224$ & $n=317$ & & & \\
\hline Female victim & $83 \%$ & $92 \%$ & 11.41 & .001 & .145 \\
\hline Male Perpetrator & $92 \%$ & $94 \%$ & 1.17 & .279 & .047 \\
\hline Day & $59 \%$ & $44 \%$ & 13.18 & $<.001$ & .156 \\
\hline $\begin{array}{l}\text { Private versus } \\
\text { Public Location }\end{array}$ & $66 \%$ & $45 \%$ & 21.55 & $<.001$ & .200 \\
\hline Multiple & $13 \%$ & $31 \%$ & 24.20 & $<.001$ & .212 \\
\hline $\begin{array}{l}\text { Known versus } \\
\text { Stranger } \\
\text { Perpetrator }\end{array}$ & $76 \%$ & $58 \%$ & 17.86 & $<.001$ & .182 \\
\hline
\end{tabular}

In the logistic regression model, the variables that were statistically significant from the chi square results were entered as predictors (i.e., female survivor, daytime attack, private versus public location, multiple perpetrators, and known versus stranger perpetrator), and the dependent variable was age group. The overall model was statistically significant, $x^{2}(5, N=541) 53.3, p=<$ .001 . According to Nagelkerke's $R^{2}, 13 \%$ of the variability in age group was accounted for by the predictors in the model. Predictive accuracy improved from 59\% to $64 \%$ using the model. The variables in our model were able to correctly classify $78 \%$ of cases perpetrated against adults, whereas $44 \%$ of cases in the child group were correctly classified using the variables in our model. 
As shown in Table 5, all of the variables, except whether the crime was committed by a known perpetrator, were statistically significant. Child compared to adult survivors were 1.61 times more likely to be attacked during the day, and 1.72 times more likely to be attacked in private as opposed to in public. Child compared to adult survivors were also significantly less likely $(O R=.458)$ to be female, and less likely $(O R=.528)$ to be attacked by multiple perpetrators.

\section{Table 5}

Table of coefficient

$\begin{array}{lrrrrr} & \text { df } & \text { Estimate } & \text { SE } & \text { Wald } X^{2} & p \\ \text { Female victim } & 1 & -0.782 & 0.29 & 7.3 & .007 \\ \text { Day } & 1 & 0.474 & 0.19 & 6.5 & .011 \\ \begin{array}{l}\text { Private versus } \\ \text { Public } \\ \text { Location }\end{array} & 1 & 0.543 & 0.21 & 6.96 & .008 \\ & & & & & \\ \text { Multiple } & 1 & -0.638 & 0.27 & 5.77 & .016 \\ \begin{array}{l}\text { Known versus } \\ \text { Stranger } \\ \text { Perpetrator }\end{array} & 1 & 0.295 & 0.34 & 1.6 & .21\end{array}$

Tables 2 and 3 present a more detailed descriptive analysis of the child and adult cases on the relationship between the perpetrator and the victim, and the locations in which the attacks took place. As can be seen, age group was significantly associated with the relationship between the perpetrator and the survivor, $X^{2}(7, N=541)=107.84, p<.001$. Children were most often victimized by neighbors, followed by strangers and family members, whereas adults were most often victimized by strangers followed by other types of perpetrators (customer, community member, friend of a friend) and spouses. Age group was also significantly associated with attack location, $X^{2}(4, N=541)=35.59, p<.001$. Children were more most often attacked at the 
perpetrator's house ( $41 \%$ of the cases), whereas adults were most often attacked in public locations ( $48 \%$ of cases).

\section{DISCUSSION}

\section{Summary of Key Findings}

We compared patterns of sexual violence committed against adults and children in Kenya during the COVID-19 pandemic. The data arose from interviews conducted by human rights defenders with survivors, and describe the experiences of 541 survivors. We found that the children in our sample were on average four years younger compared to national surveys of children in Kenya. ${ }^{32,33}$ Further, compared to adults, children were more likely to be attacked during the day, in private as opposed to public locations, by lone perpetrators, and by neighbors. In what follows, we discuss our findings in relation to existing research and draw implications for policy.

\section{Comparisons to Current Literature}

There were significant numbers of children in our sample, which is unsurprising, as approximately half of GBV survivors are children during humanitarian crises. However, the children in our sample were 12 years old on average, which is 4 years younger than the nationally representative samples taken pre-pandemic. ${ }^{32,33}$

We also found that children were 1.61 times more likely than adults to be attacked during the day. This could be attributed to the way that children and adults were spending their time during the pandemic. Because schools were closed, and there was no provision of any alternative safe spaces, children may have been often left alone or under the care or supervision of neighbors or community members, which may have made them more vulnerable to attack in some instances. Children were more likely to be attacked in private as compared to public locations. Adults in 
our sample were about equally likely to be attacked during the day as at night. Further, in keeping with previous research, significantly more adults were violated by multiple perpetrators compared to children. ${ }^{36}$

The proportion of boys in the children's group was larger than the proportion of men in the adult's group. This may reflect differential rates of victimization for men compared to boys. Another possible reason is that sexual violence against men compared to boys is disclosed less often. The legal definition of rape in Kenya, like many countries, requires 'vaginal penetration', which reinforces sociocultural notions that men cannot be sexually victimised. ${ }^{34}$ Further, the tendency for people to believe that the victimisation of men is harmless, coupled with self-blame and fear on the part of victims that their community and family will react negatively towards them, discourage men from seeking help, and reporting sexual offenses to the police. ${ }^{35}$

The children and adults in our sample were more likely to be violated by someone they knew than a stranger. For adults, perpetrators were most likely to be strangers, followed by neighbors and community members, and spouses. The most common perpetrators for children were neighbors, followed by strangers, and family members. Adults were violated by strangers more frequently because they were often attacked when the opportunity struck, such as while walking to or from work, whereas children were violated by neighbors when they were left under their supervision due to school closures and their parents' job requirements. ${ }^{25}$ Children were attacked by neighbors and in the perpetrators' houses at higher rates than adults. Although both groups were more likely to be violated by someone they knew as opposed to a stranger, and in both groups more than half of the perpetrators were known to the survivor, there is a high proportion of stranger compared to known assailants in both age groups. There were a number of instances 
in our data set in which neighbors invited children to use a computer or access the Internet, and then assaulted them once they were inside the neighbor's residence.

\section{Strengths and Limitations}

This research was conducted in partnership with frontline, survivor-led organisations, using a prospective study design, which are key strengths. This enabled us to systematically and rapidly study sexual violence in Kenya during the pandemic, even though there were considerable physical distancing measures in place. Further, our data are unusually rich. The data provide detailed information about survivors and perpetrators, where and when the incidents occurred, which allowed for studying patterns of sexual violence. There are also several limitations of our

study to note. First, the sample was comprised of individuals who were seeking help in accessing vital services. Hence, inferences about patterns nationally in Kenya cannot be made because the data may not be a representative. Further, our data do not provide information about sexual violence trends. Like many countries around the world, sexual violence is underreported, and detailed, longitudinal information about sexual violence incidents are lacking. Consequently, researchers struggle to make inferences about whether patterns of violence are changing during COVID-19. ${ }^{37}$ For example, the Demographic and Health Survey in Kenya, which is a nationally representative survey of adults occurring every five years, does not gather in-depth information about violations. Similarly, the national Violence Against Children Survey in Kenya, conducted in 2010 and 2019, does not gather in depth information. We also had to rely on second-hand accounts from guardians of sexual violence against children, owing to a lack of trained personnel and adequate resources in Kenya for interviewing children. Some children were too young to be interviewed, with the youngest victim being just seven-months old. Finally, our model better accounted for patterns of violence against adults compared to children. This is because some of 
the factors we analysed were more applicable to adults than children (e.g., employment, romantic relationships, being alone in public).

\section{Recommendations and Conclusion}

We urge policy makers to make sure that government COVID-19 emergency management and recovery planning adequately covers sexual and gender-based violence. This should include the provision of adequate alternative safe venues when schools are closed. Further, the implementation of emergency routes that enable survivors to access health, security, and protection services need to be a part of government plans. Survivors should also be exempted from lockdown requirements so they can access services. Further, the medico-legal response to SGBV can be strengthened by expediting restraining orders and prosecutions, and by establishing 'one-stop' centres to allow survivors to access essential services, and authorities to collect evidence, all in one location. In conclusion, governments must invest in real-time data collection and analysis systems to capture the nature of current sexual violence incidents and study regional trends. This would allow authorities to identify crime hot spots and violations being perpetrated by the serial offenders, and to monitor the accessibility of vital services to help ensure that survivors have support. These efforts should be survivor-centred, and involve survivors in the implementation and evaluation of the systems. 


\section{References}

1. Garcia-Moreno C, Pallitto C, Devries K, Stock1 H, Watts C, Abrahams N. Global and regional estimates of violence against women: prevalence and health effects of intimate partner violence and nonpartner sexual violence. Geneva: WHO; 2013.

2. Odhiambo A. "They Were Men in Uniform" Sexual Violence Against Women and Girls in Kenya's 2017 Elections USA: Human Rights Watch 2017.

3. Bellizzi S, Nivoli A, Lorettu L, Ronzoni AR. Human rights during the COVID-19 pandemic: the issue of female genital mutilations. Public health (London). 2020;185:53-4.

4. Health Mo. First Case of Coronavirus Disease Confirmed in Kenya health.go.ke: Ministry of Health; 2020 [

5. Ritchie H, Ortiz-Ospina E, Beltekian D, Mathieu E, Hasell J, Macdonald B, et al. Kenya: Coronavirus Pandemic Country Profile ourworldindata.org: ourworldindata.org; 2020 [

6. Flowe H, Rockowitz S, Rockey J, Kanja W. Sexual and Other Forms of Violence During the COVID-19 Pandemic Emergency in Kenya. The University of Birmingham 2020.

7. Bearak M, Ombuor R. Kenya's coronavirus curfew begins with wave of police crackdowns. The Washington post. 2020.

8. UNFPA. As pandemic rages, women and girls face intensified risks 2020 [Available from: https://www.unfpa.org/news/pandemic-rages-women-and-girls-face-intensified-risks.

9. Marsh M, Purdin S, Navani S. Addressing sexual violence in humanitarian emergencies. Glob Public Health. 2006;1(2):133-46.

10. Dara Kay C, Ragnhild N. Sexual violence in armed conflict: Introducing the SVAC dataset, 1989-2009. Journal of peace research. 2014;51(3):418-28.

11. Sloand E, Killion C, Yarandi H, Sharps P, Lewis-O'Connor A, Hassan M, et al. Experiences of violence and abuse among internally displaced adolescent girls following a natural disaster. J Adv Nurs. 2017;73(12):3200-8.

12. Schwartz DA, Anoko JN, Abramowitz SA. Pregnant in the Time of Ebola Women and Their Children in the 2013-2015 West African Epidemic [text]. Cham: Springer International Publishing : Imprint: Springer,; 2019.

13. Fisher S. Violence Against Women and Natural Disasters: Findings From Post-Tsunami Sri Lanka. Violence Against Women. 2010;16(8):902-18.

14. Le Masson V, Lim S, Budimir M, Podboj J. Disasters and violence against women and girls. Can disasters shake social norms and power relations? London, England: Overseas Development Institute; 2016.

15. Watch HR. Kosovo: Rape as a Weapon of "Ethnic Cleansing. New York, NY; 2000.

16. Lives Blown Apart: Crimes Against Women in Times of Conflict. London, England: Amnesty International; 2004.

17. Intitiative HH, Institute OS. Characterizing Sexual Violence in the Democratic Republic of the Congo: Profiles of Violence, Community Responses, and Implications for the Protection of Women. Cambridge, MA: Harvard University 2009.

18. Stark L, Wessells M. Sexual Violence as a Weapon of War. JAMA. 2012;308(7):677-8. 
19. Guterres A. Conflict Related Sexual Violence: Report of the United Nations Secretary General. United Nations; 2019.

20. O'Brien M, Tolosa MX. The effect of the 2014 West Africa Ebola virus disease epidemic on multi-level violence against women. International journal of human rights in healthcare. 2016;9(3):151-60.

21. Chandan JS, Taylor J, Bradbury - Jones C, Nirantharakumar K, Kane E, Bandyopadhyay S. COVID-19: a public health approach to manage domestic violence is needed. The Lancet Public Health. 2020;5(6).

22. Mittal S, Singh T. Gender-Based Violence During COVID-19 Pandemic: A MiniReview. Frontiers in Global Women's Health. 2020;1(4).

23. Bradbury-Jones C, Isham L. The pandemic paradox: The consequences of COVID-19 on domestic violence. J Clin Nurs. 2020;29(13-14):2047-9.

24. UNFPA. Millions more cases of violence, child marriage, female genital mutilation, unintended pregnancy expected due to the COVID-19 pandemic 2020 [Available from: https://www.unfpa.org/news/millions-more-cases-violence-child-marriage-female-genitalmutilation-unintended-pregnancies.

25. Simba H, Ngcobo S. Are Pandemics Gender Neutral? Women's Health and COVID-19. Frontiers in Global Women's Health. 2020;1(8).

26. Usher K, Bhullar N, Durkin J, Gyamfi N, Jackson D. Family violence and COVID-19: Increased vulnerability and reduced options for support

. International Journal of Mental Health Nursing. 2020;29(4).

27. Onyango M, Resnick K, Davis A, Shah R. Gender-Based Violence Among Adolescent Girls and Young Women: A Neglected Consequence of the West African Ebola Outbreak: Medical, Anthropological, and Public Health Perspectives. 2019. p. 121-32.

28. Giannini S, Albrectsen AB. COVID-19 school closures around the world will hit girls hardest UNESCO; 2020 [

29. Ethical and safety recommendations for intervention research on violence against women. Building on lessons from the WHO publication Putting women first: ethical and safety recommendations for research on domestic violence against women. Geneva: World Health Organization; 2016.

30. The Data Protection Act, 24 (2019).

31. McHugh ML. The chi-square test of independence. Biochem Med (Zagreb). 2013;23(2):143-9.

32. Kenya. Ministry of H, Kenya National Bureau of S, National ACC, Kenya Medical Research I, National Council for P, Development, et al. Kenya demographic and health survey, 20142015.

33. Services MoLaSPoKDoCs. Violence against Children in Kenya: Findings from a National Survey, 2019. Kenya; 2019.

34. Clayton MB, Mace B. Male Victims of Sexual Assault: Phenomenology, Psychology, Physiology. J Am Acad Psychiatry Law. 2011;39(2):197-205.

35. Hlavka HR. Speaking of Stigma and the Silence of Shame:Young Men and Sexual Victimization. Men and Masculinities. 2017;20(4):482-505.

36. Edinburgh L, Pape-Blabolil J, Harpin SB, Saewyc E. Multiple perpetrator rape among girls evaluated at a hospital-based Child Advocacy Center: Seven years of reviewed cases. Child Abuse Negl. 2014;38(9):1540-51. 
37. Chelangat N, Kipyego E, Kimani S, Aseka L, Munyao M, Amimo S. Trapped within a lockdown: understanding sexual and gender-based violence during the Covid-19 period. . Nairobi: Professional Criminologists Association of Kenya; 2020. 